\title{
Formation of Surface Nano- and Textured Austenite Induced by Pulsed Electron Beam Irradiation under Melting Mode
}

\author{
K. M. Zhang ${ }^{1}$ and J. X. Zou ${ }^{2,3}$ \\ ${ }^{1}$ School of Materials Engineering, Shanghai University of Engineering Science, Shanghai 201620, China \\ ${ }^{2}$ Shanghai Engineering Research Center of Mg Materials and Applications \& National Engineering Research Center of \\ Light Alloy Net Forming, Shanghai Jiao Tong University, Shanghai 200240, China \\ ${ }^{3}$ State Key Laboratory of Metal Matrix Composite \& School of Materials Science and Engineering, Shanghai Jiao Tong University, \\ Shanghai 200240, China \\ Correspondence should be addressed to K. M. Zhang; zhangkm@sues.edu.cn
}

Received 18 December 2012; Accepted 25 January 2013

Academic Editor: Gang Ji

Copyright ( 92013 K. M. Zhang and J. X. Zou. This is an open access article distributed under the Creative Commons Attribution License, which permits unrestricted use, distribution, and reproduction in any medium, provided the original work is properly cited.

\begin{abstract}
We report in this paper an interesting phenomenon associated with low-energy high-current pulsed electron beam (LEHCPEB) treatment: surface nanograined and textured austenite formation under the melting treatment mode. The treatment induces superfast heating and melting followed by a rapid solidification and cooling of the material surfaces. As a result, nano-structured surface layers can be achieved quite easily. Examples of nanoaustenite formation with special texture state in the modified surface layer of AISI D2 steel and NiTi alloy will show the potential for surface nanocrystallization of materials with improved properties by LEHCPEB technique.
\end{abstract}

\section{Introduction}

Recently, the application of energetic beams such as ion, electron, laser, and plasma has been of increasing interest to modify the surface of metallic materials [1-3]. The main feature of these pulsed systems lies in their high power density of $10^{9}-10^{12} \mathrm{~W} / \mathrm{cm}^{2}$ acting at the target surface within short durations. Among these pulsed beam techniques, the low-energy high-current pulsed electron beam (LEHCPEB) is relatively new $[3,4]$. The simplicity and reliability are the advantages of this technique over pulsed laser and ion beam treatments, with potential industrial applications [3]. The high-density electron pulses of short durations induce dynamic temperature fields in the surface layers, leading to the superfast heating, possible melting, and even evaporation. This is followed by a rapid solidification and cooling of the material surface. As a result, nonequilibrium microstructures, such as supersaturated solid solution, nanosized grain, and even amorphous phase formations, can be achieved in the resolidified layer. In addition, a dynamic stress field is formed that causes intense deformation in the material sublayers [5]. These mechanisms can generate a surface layer with improved physical, chemical, and strength properties that are often unattainable with conventional surface treatment techniques $[3,4]$.

During the past few decades, nanostructured materials have been studied extensively due to the fact that they have many advantages over conventional coarse-grained materials [6]. Especially, nanoaustenization has long been the objective of metallurgists to achieve combined high toughness of the austenite phase and high strength of the nanostructure. Rapid solidification and severe plastic deformation may be two alternative candidates for such a purpose. In some previews works, fine structured austenite steels were obtained by various solidification-related techniques, such as thermal spray, melt spinning, and laser treatment with the aim of producing the so-called "super steel" high strength steel with high ductility [7-9]. However, fine austenitic steel with a single phase structure is not achieved below $400 \mathrm{~nm}$ yet due to many factors concerning difficulties of preparation 
techniques and designing of fabrication route. Sever plastic deformation methods, such as equal channel angular processing and mechanical attrition treatment, are known to be able to produce nanostructured materials with grain size down to several nms $[10,11]$. However, austenite is usually metastable; that is, it tends to transform into martensite. For example, by using repeated cold rolling and equal channel angle processing, austenitic stainless steels can be nanocrystallized $[7,8]$, but the final microstructure always presents a mixture of martensite and austenite due to the straininduced martensitic transformation during these processing. Further high-temperature annealing is necessary to revert the martensite to austenite. As a side effect, the size of the austenite grains will increase to micrometer size at the same time.

In many cases, the nature of the material surface is of major importance, in particular for fatigue, corrosion, and wear resistance properties which are of interests for industrial applications. Therefore, instead of producing bulk nanostructured materials, nanocrystallization of the surface can be an optimum alternative [10-12]. K. Lu and J. Lu first proposed the concept of surface nanocrystallization of materials through chemical, physical, and mechanical methods [10]. By using mechanical attrition treatment, they obtained nanostructured surface layers having better mechanical and chemical properties on different metallic materials [11]. The purpose of the present work is to show the surface nanoaustenite formations in metallic materials induced by the LEHCPEB treatment.

\section{Experimental Procedure}

2.1. Starting Materials. Two kinds of materials were selected to be treated by LEHCPEB, a cold worked die steel (AISI D2) and an NiTi shape memory alloy. The chemical composition of the D2 steel is C 1.4 1.6200 wt\%, Cr 11 13 wt\%, Mo 0.7$1.2 \mathrm{wt} \% \mathrm{~V} \sim 1 \mathrm{wt} \%$, Mn $0.6 \mathrm{wt} \%$, Si $0.6 \mathrm{wt} \%$, Fe balance. The D2 steel samples were austenitized at $1020^{\circ} \mathrm{C}$ for $30 \mathrm{~min}$ followed by water quenching [13]. The steel was subsequently tempered at $200^{\circ} \mathrm{C}$ for 3 hours. The above treatment procedure results in an initial structure of mixed carbides $\left(\mathrm{Cr}_{7} \mathrm{C}_{3}\right.$ type $)$ and tempered martensite. The as-received $\mathrm{Ni}(50.6$ at $\%) \mathrm{Ti}$ shape memory alloy was hot rolled at $750^{\circ} \mathrm{C}$ by multipasses in the form of a nearly rounded bar having a diameter of about $12 \mathrm{~mm}$ [14]. This processing led to a recrystallized structure having a very weak (less than two time random) and broad $\langle 110\rangle$ fiber texture // to the rolling direction. The initial grain size was about $10 \sim 50 \mu \mathrm{m}$. The specimens for the LEHCPEB treatment were cut perpendicularly to the rolling axis into $2 \mathrm{~mm}$ thick discs. Prior to the LEHCPEB treatments, the disc surfaces were polished down to $1 \mu \mathrm{m}$ diamond paste, and the specimens were ultrasonically cleaned in acetone.

2.2. Experimental Conditions. The electron beam system used in this work is a "Nadezhda-2-" type LEHCPEB source. It can produce electron beams with the following characteristics: an electron energy of 10 to $40 \mathrm{keV}$; a pulse duration of about $1 \mu \mathrm{s}$; an energy density ranging from 0.5 to $5 \mathrm{~J} / \mathrm{cm}^{2}$; and a cross-section area that can be adjusted between 10 and $50 \mathrm{~cm}^{2}$. The electron beam is generated at an explosive emission graphite cathode. The accelerating voltage, magnetic field intensity, and the anode-collector distance are the controlling parameters for the beam energy density. For more details about the LEHCPEB system, the readers can refer to references $[3,4]$. The electron-beam treatment parameters were as follows: an accelerating voltage of $27 \mathrm{kV}$ and an energy density of $\sim 2.5 \mathrm{~J} / \mathrm{cm}^{2}$. The samples investigated here were treated for 5,10 , and 20 pulses and with a pulse duration of $1.5 \mu$ s. The dwell time between each pulse was $10 \mathrm{~s}$. The parameters were set so that in both cases the materials' surfaces were treated under "melting" mode, which is different from the "evaporating" mode where the surface can reach boiling point during treatment.

2.3. Microstructure and Phase Characterization. Conventional X-ray diffraction $(\theta-2 \theta$ mode) was carried out with a $\mathrm{Cu}-\mathrm{K}_{\alpha}$ radiation source on a SHIMADZU XRD-6000 apparatus to analyze the phase state at the sample surface. The texture analysis on D2 steel samples was carried out using a D8 Advance Bruker AXS X-ray goniometer equipped with an Eulerian cradle $\chi$ stage. The $\mathrm{Cr}-\mathrm{K}_{\alpha}$ radiation was selected for the texture analysis in order to better distinguish and separate the peaks from the $\alpha$ and $\gamma$ phases. In some cases, to limit the X-ray penetration depth and thereby investigate only the thin melted layer present at the surface, low incident beam X-ray diffraction was done with an incident angle set at $2^{\circ}$. A JEOL 6500F-type field emission gun scanning electron microscope (FEG-SEM) equipped with an electron backscattering diffraction (EBSD) attachment was used to observe surface morphologies and gain more information about the microstructure and texture state of the melted zone on NiTi samples. For the EBSD analysis, the SEM was operated at $15 \mathrm{kV}$ with the sample tilted by $70^{\circ}$.

\section{Results}

3.1. Nano- and Textured Austenite in Irradiated D2 Steel. Figure 1(a) shows the evolution of the XRD patterns of LEHCPEB-treated D2 steel samples with the number of pulses [15]. The starting material contained two phases: ferrite $(\alpha-\mathrm{Fe})$ and carbide having the $\mathrm{Cr}_{7} \mathrm{C}_{3}$ structure. After the LEHCPEB bombardment, the XRD patterns are observed to be changed somehow dramatically. Concerning the $\mathrm{Cr}_{7} \mathrm{C}_{3}$ phase, it is clear that the carbide peaks tend to disappear after the LEHCPEB treatments. Concerning the $\alpha$ phase, it is interesting to note that some of the peaks in the sample treated for 5 pulses have close neighbours. A splitting of the (200) peak is usually found in newly formed martensite having sufficient amount of $\mathrm{C}$ to reveal its quadraticity. It is interesting to note that this peak splitting is no longer observed after 25 pulses of LEHCPEB treatment. Finally, some new peaks are present in the XRD patterns. They were verified to be from the $\gamma$-Fe phase. The peak intensity of the $\gamma$-Fe phase increases with the number of pulses, indicating that the volume fraction of the $\gamma$ phase detected by XRD increases. 


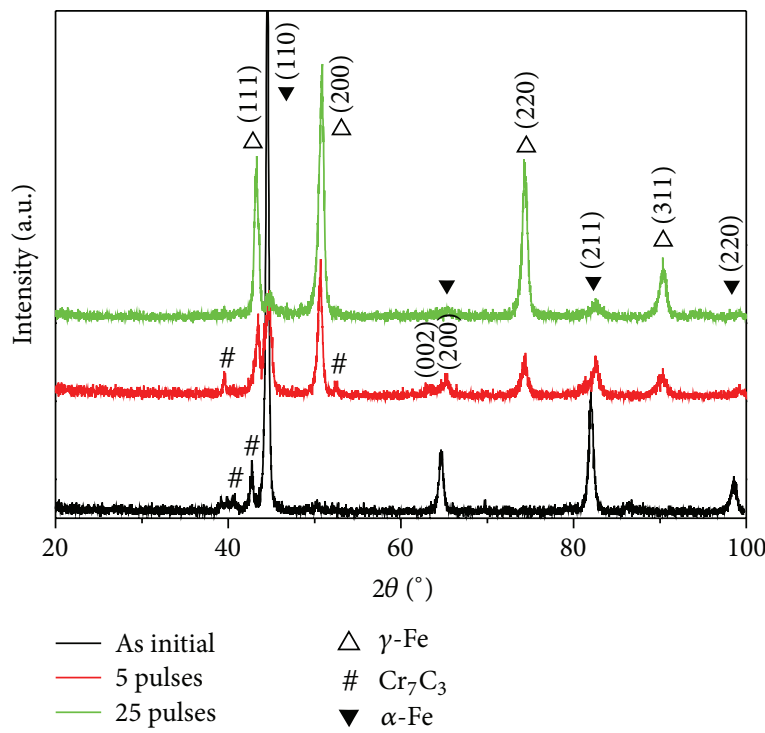

(a)

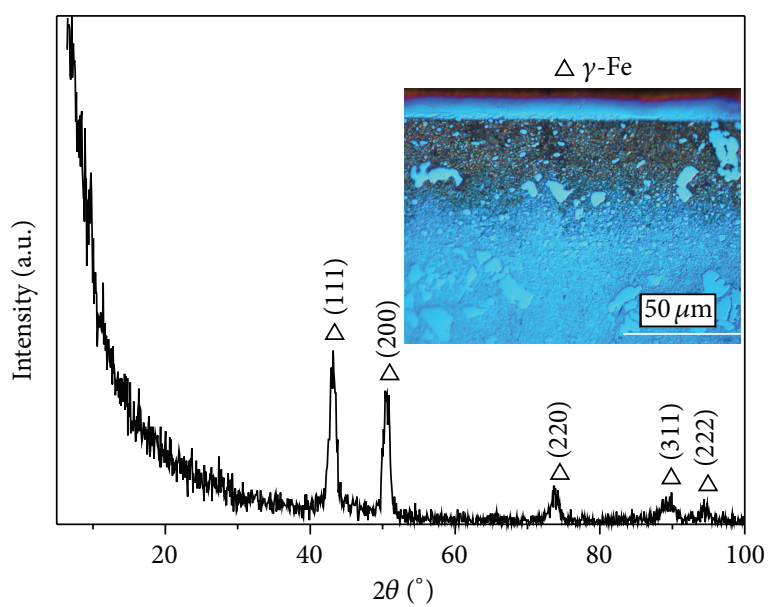

(b)

FIGURE 1: (a) XRD patterns of the untreated and treated D2 steel samples. (b) Low incident beam XRD pattern of the 25-pulsed sample; a typical cross-sectional OM picture is shown inset.

Figure 1(b) shows the low incidence beam X-ray diffractogram recorded on the sample treated for 25 pulses. It only shows the presence of the $\gamma$ peaks. This indicates that the surface layer is mainly composed of the $\gamma$ phase. The typical cross-sectional micrograph of the etched sample after the LEHCPEB treatment for 25 pulses is shown in the inset of Figure 1(b). The "white" layer visible on the surface, which appears with a completely different contrast from the rest of the material, corresponds to the melted layer. No carbides or grain boundaries could be observed in this layer even after deep etching. The average depth of the melted layer is $4.4 \mu \mathrm{m}$ after 25 pulses. Below the melted layer are the heat affected zone and substrate containing large amount of carbides.

Figure 2 shows a typical SEM micrograph taken on the 5-pulsed sample. Needle-like structures are clearly observed, which tend to be grouped and connected to each other. This needle-like aspect suggests the presence of martensite. It was confirmed by EBSD measurements that those needle-like structures are martensite and the rest are austenite [15]. A high magnification SEM-FEG image of the 25 pulses treated D2 steel is shown in Figure 2(b). It reveals very fine grains or subgrains having a size of about 100 150 $\mathrm{nm}$, which cover the whole surface. Figure 2(c) shows a typical TEM bright field image from the melted layer of the 25-pulsed sample. The majority of the structure consisted of the $\gamma$ phase, which was directly grown from the melt and was retained down to room temperature. Although the cooling rate was as high as $10^{7} \mathrm{~K} / \mathrm{s}$, the martensitic transformation was completely suppressed [16]. Such an effect is due to the increased stability of the austenite phase by grain size constraining effect and by the austenite stabilized alloying of $\mathrm{C}$ into the melt. Various TEM images, taken from different locations in the thin foil, showed that the cell size of the $\gamma$ phase was in the range of $50-200 \mathrm{~nm}$. A careful look at the micrograph in Figure 2(c) reveals also very fine precipitates. Their size is below $10 \mathrm{~nm}$. They are often present at the grain boundaries and in particular most often at triple junctions, as arrowed in Figure 2(c).

Figure 3 shows the normalized inverse pole figure corresponding to the $\gamma$ phase on the 25-pulsed sample measured by XRD goniometer [14]. The intensity in the vicinity of (200) pole is about 1.8 is slowly decreasing when approaching the other two poles. This indicates the presence of a $\langle 200\rangle$ fiber texture component parallel to the normal direction of the sample with a large spread around this ideal orientation. In addition, the higher intensity around (220) pole (about 2.1) and its fast decreasing show also the presence of a sharper $\langle 220\rangle$ component. Although clearly depicted, these two texture components are rather weak, having maximum slightly above 2 times random. The very low intensity at (111) pole confirms the two fibers and indicates that the $\langle 220\rangle$ and $\langle 200\rangle$ crystallographic directions along the normal direction of the sample are created at the expense of orientations in the vicinity of $\langle 111\rangle$.

3.2. Nano- and Textured Austenite in Irradiated NiTi Alloy. $\mathrm{XRD}$ analysis was also carried out on the NiTi alloy samples before and after the LEHCPEB treatments. Examples of diffractograms are shown in Figure 4. For the initial state, the observed peaks correspond to the NiTi (B2 structure) austenite phase and the $\mathrm{NiTi}_{2}$ precipitates. After the LEHCPEB treatment with 5 pulses, peaks corresponding to the NiTi

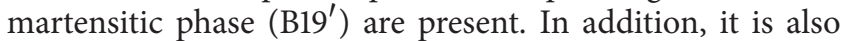
clearly visible that the diffraction peaks of the $\mathrm{NiTi}_{2}$ phase have disappeared, which is a consequence of the surface purification effect from precipitates in the surface layer [17]. However, the intensity of the peaks corresponding to NiTi martensite became weaker after 10 pulses and almost 


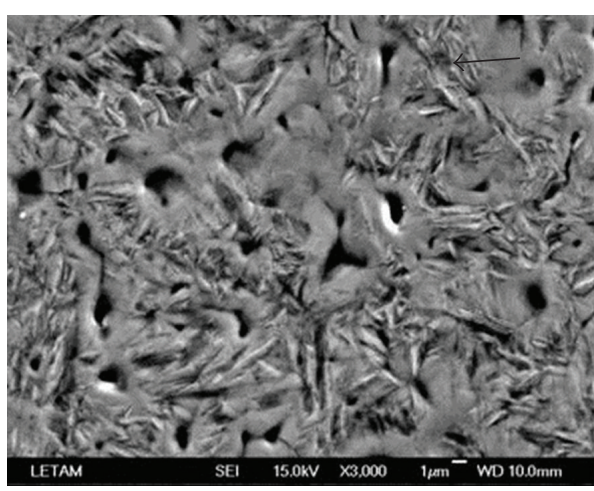

(a)

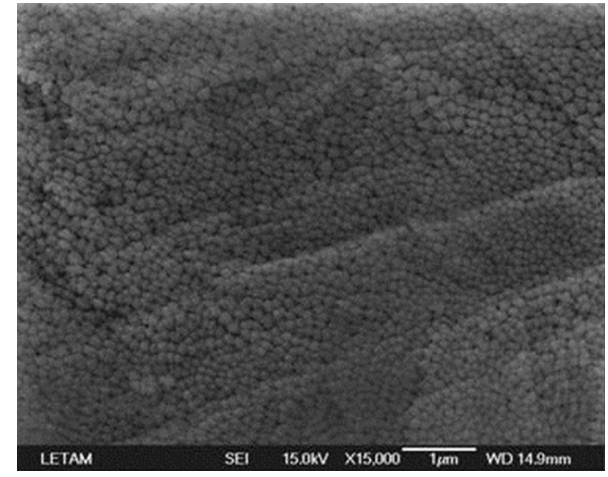

(b)

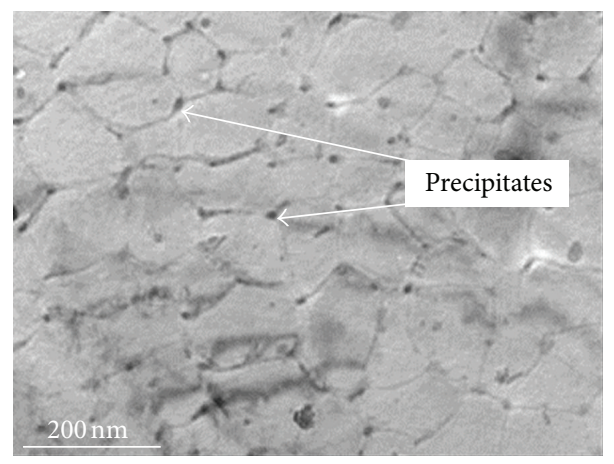

(c)

FIGURE 2: Typical SEM surface morphology on the 5-pulsed D2 sample (a) and high magnification SEI (b) surface morphologies of the sample treated with 25-pulses. Typical TEM morphology in the melted layer of the 25 pulsed sample (c).

disappeared after 20 pulses. This indicates that the fraction of martensite in the surface layer decreases with the number of pulses, a similar case to that observed on the D2 steel samples.

To gain more information about the microstructure and texture issued from the solidification of the surface melted zone, FEG-SEM observations and EBSD analysis were carried out at the top surface of the treated NiTi samples. Figure 5 shows a typical SEM micrograph of the sample LEHCPEB treated for 5 pulses under backscattering condition. Some straight bands having brighter contrast are clearly visible, close to the crater formation region. This is reasonable because the martensitic transformation in this alloy was triggered by the high stress field induced by the LEHCPEB treatment, and the stress field near crater formation region is higher due to the shock wave formation [18]. The dark spots, often located in the crater centers, are $\mathrm{NiTi}_{2}$ precipitates, which are the initial sites for crater formations. The rest area is covered by fine grains and a network of fine shrinkage voids. Much like the 25-pulsed D2 steel sample, a high magnification SEM-FEG image of the 20 pulses treated NiTi (Figure 5(b)) reveals again very fine grains having a size of about $100 \mathrm{~nm} \sim$ $1 \mu \mathrm{m}$, which cover the whole surface.

Figures 6(a) and 6(b) give a typical EBSD OIM map on the 20 pulses treated NiTi sample as well as its related pole figures. All the grains on the top surface were indexed as corresponding to the NiTi austenitic phase having the B2 structure and no martensitic phase could be indexed. Indeed, the map in Figure 6(a) is almost completely dominated by grains having a green color (medium gray), which corresponds to grains having a $\{110\}$ plane perpendicular to the normal direction. Besides, some red-colored grains (deep gray), having their $\{100\}$ plane perpendicular to the normal direction, are also present. The pole figures (Figure 6(b)), containing rings, depict a fiber type of texture. It consists in fact of two major components: a major $\langle 110\rangle / / \mathrm{ND}$ component to which it is associated with a very weak $\langle 100\rangle / /$ ND one. The size distribution of the austenite phase grains is shown in Figure 6(c). After the LEHCPEB treatment with 20 pulses, the rapid solidification leads to a fine grain structure with mean grain size of about $380 \mathrm{~nm}$.

\section{Discussion}

Usually, the LEHCPEB-modified surface layer can be divided into three regions from the cross-sectional view having different depths in the treated material [19-21]: (i) a melted and rapidly solidified layer on the top surface $(\sim 1-10 \mu \mathrm{m})$, (ii) a heat affected zone (HAZ $\sim 10-100 \mu \mathrm{m})$, and (iii) a stress wave affected zone $(\sim 100-1000 \mu \mathrm{m})$.

During the pulsed electron beam irradiation, the material adjacent to the zone of energy transfer is rapidly heated, leading to the formation of a nonequilibrium temperature field propagating into the material. Simultaneously, two kinds of stresses are generated, that is, the thermoelastic stress and 


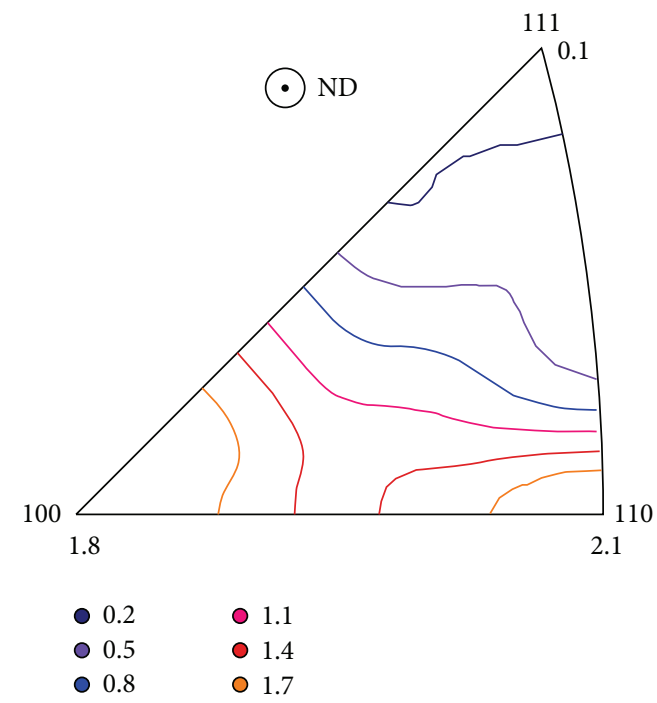

FIGURE 3: Inverse pole figure of the austenite on the 25-pulsed D2 steel sample measured by XRD.

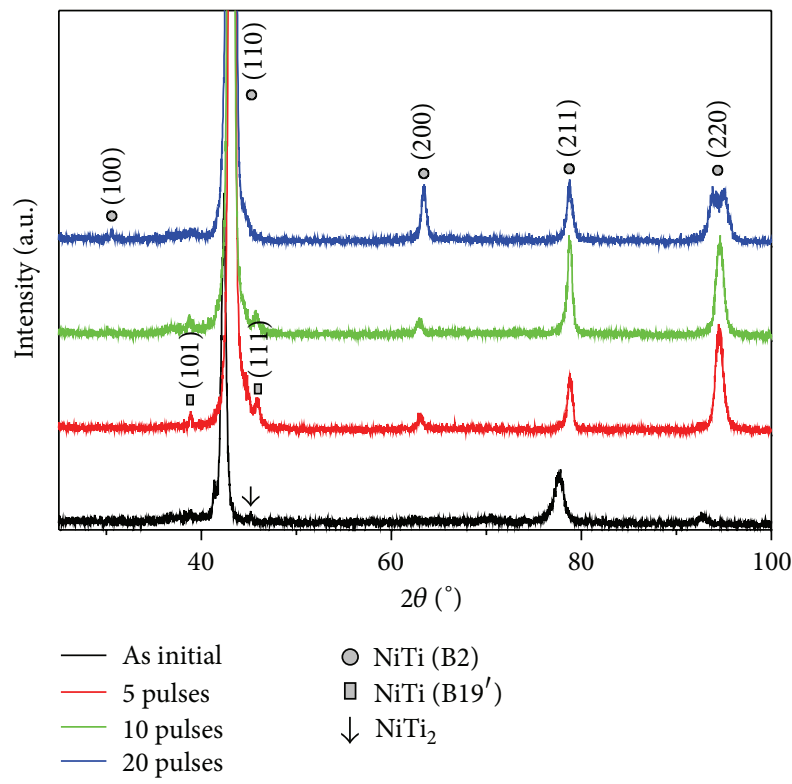

FIGURE 4: XRD patterns of the untreated and treated NiTi alloy samples.

the quasi-static thermal stress $[18,22]$. When the material top surface layer is heated up, local melting can also occur preferentially below the surface at preferential sites such as second phase particles or crystallographic discontinuities. During the melting, the constrained melted pockets of mater can be expulsed towards the outer covering solid surface, leading to the eruptive cratering phenomena, and a recoiled impulsion will be exerted against the underlying substrate [18]. This leads to the formation of local high-gradient stress fields in the vicinity of these structural discontinuities. The stress is thus generated during the process of eruption namely, the shock thermal stress can propagate along the direction of the electron beam in the material matrix and fade away when the eruption event finishes. When the electron beam pulse is completed, the surface layer cools down rapidly while the thermoelastic and quasi-static thermal stresses evolve temporally until the heat balance is reached in the sample [22].

The nanostructured austenite formation after LEHCPEB treatment can be mainly attributed to the rapid solidification that occurs at the surface layer. As mentioned before, the $\mathrm{Cr}$ and $\mathrm{C}$ contents in the melted layer of D2 sample increase with the number of pulses, and, thereby, the melt composition becomes closer to the eutectic point. Therefore, the melt gets stabilized, and the undercooling during rapid solidification increases [23]. This must lead to an increase in the nucleation rate within the melt with the number of pulses. In addition, it was also shown that the addition of small-sized atoms, for example, $\mathrm{B}$ into $\mathrm{Ni}_{70} \mathrm{Cu}_{30}$ alloy, can favour the grain refinement effect by reducing the crystal growth rate [23]. In this case, carbon will play the same role, as already shown in an Mg alloy [24]. Thus, the drastic grain refinement observed here with the pulse numbers must result from the combined effects of an increased nucleation rate and a lower grain growth. An interesting phenomenon found in the present work was the stabilization of austenite after the repeated actions of the beam and the rapid solidification process. This phase directly grows from the melt. Because of the very high cooling rate $\left(\sim 10^{7} \mathrm{~K} / \mathrm{s}\right)$ and high thermal stress (hundreds of $\mathrm{MPa}$ ) undergone at the surface of the sample, it is expected that the high temperature $\gamma$ phase transforms into martensite undercooling. In the case of D2 steel, however, it is likely that the dissolution of the large carbide was almost complete so that the amount of $\mathrm{C}$ in the austenite must have significantly depressed the Ms temperature, and, consequently, the martensitic transformation was avoided. Besides, the inhibition of the martensitic transformation is also suppressed due to the ultrafine grain size of the austenite phase formed in this melted layer by the rapid solidification process [16].

In both cases, we have noticed that the phase transformation route with the number of pulses is similar. The martensitic transformation occurred only at the early stage of treatment, that is, 5 pulses. Then it was suppressed by dissolution of carbides or by the grain size constraining effect with sufficient number of pulses. Here, martensitic transformation may play an important role for the grain refining process. It can divide one grain into some separate parts and by which the grain can be refined. This process occurred repeatedly during each pulse, until the grain is fine enough that martensitic transformation cannot occur any more. The grains showed somehow an "inherent" behaviour.

Another interesting observation revealed in this work is the presence of the mixed $\langle 100\rangle+\langle 110\rangle$ fiber texture for the rapidly solidified D2 steel and NiTi B2 layers. Generally, a growth process is done along the thermal gradient direction following well-defined crystallographic directions which, for cubic materials, are the $\langle 100\rangle$ directions [2527]. The texture development can be influenced at the two stages controlling the solidification process that starts by nucleation and continues with growth. As the LEHCPEB 


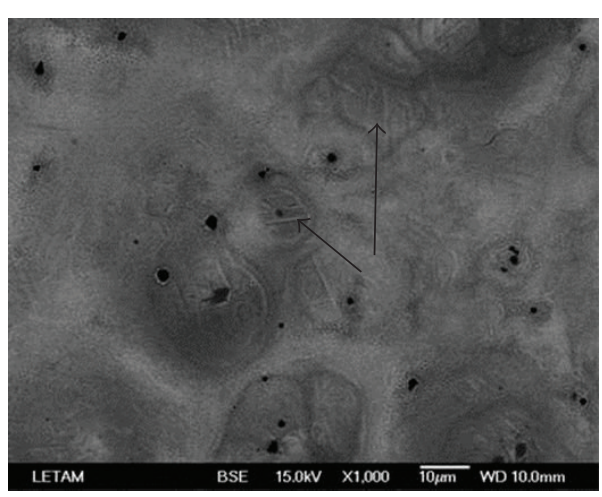

(a)

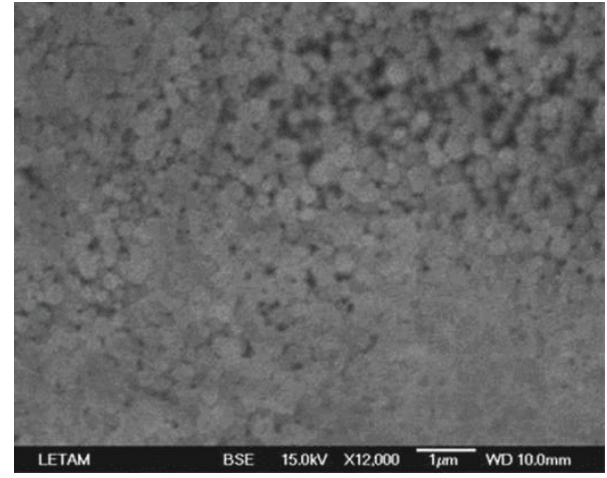

(b)

FIGURE 5: Typical BSE surface morphology on the 5-pulsed NiTi sample (a) and high magnification BSE (b) surface morphology of the sample treated with 20 pulses.

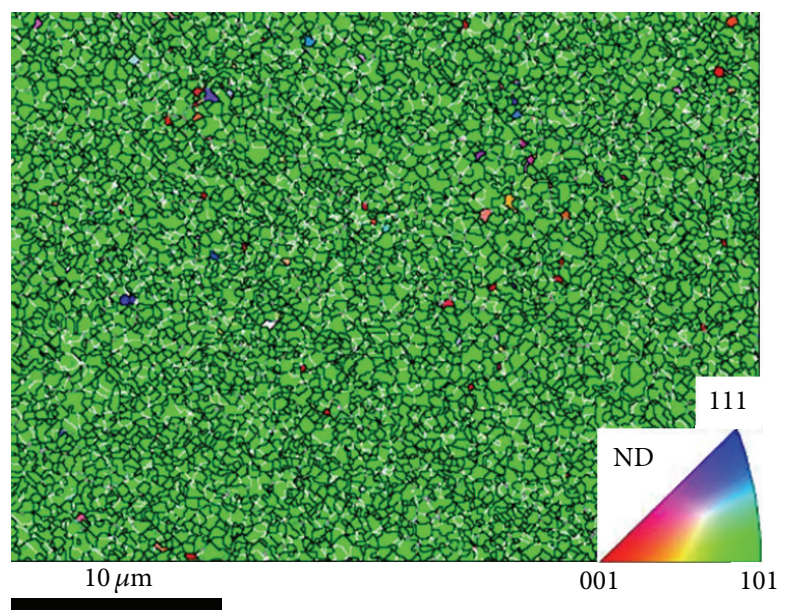

(a)

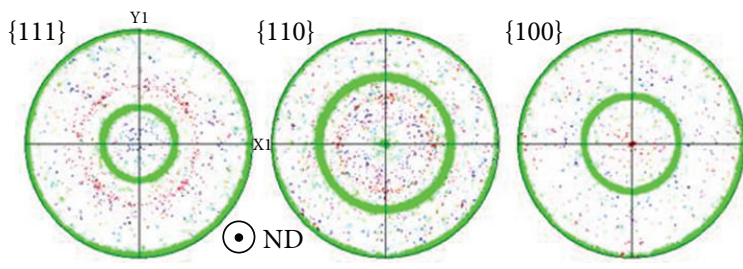

(b)

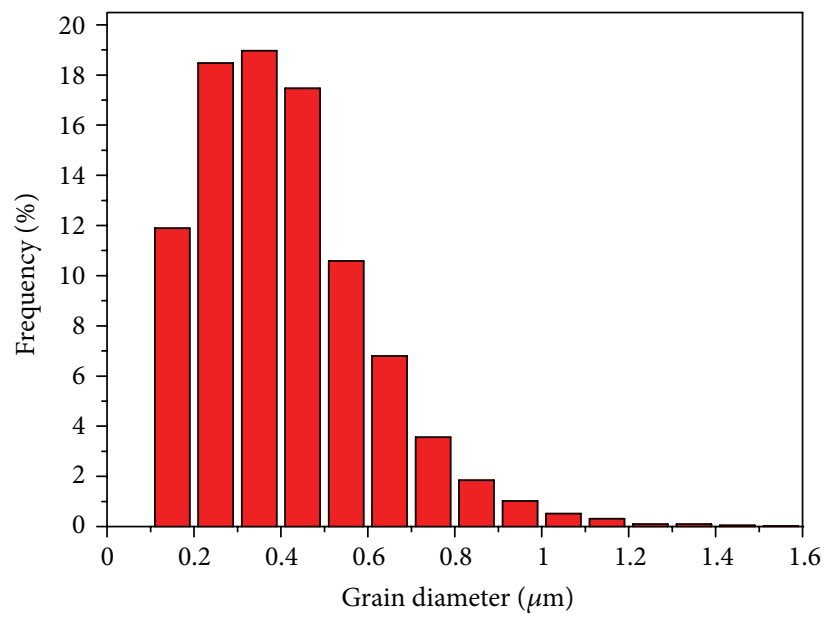

(c)

FIgURE 6: Typical EBSD OIM image of the surface 20-pulsed NiTi sample (a), its corresponding pole figures (b) and the grain size distribution (c). 
process leads to resolidification onto an unmelted substrate, the nucleation stage can be affected by the orientation of the material from which the melted layer resolidifies. However, the initial D2 steel doesnot have a specific texture, and the initial NiTi alloy shows that only a very weak (110) fiber. This means that the growth of the austenite from melt is not an epitaxial one. Changes in the growth directions with respect to solidification conditions have been reported in transparent materials [28] as well as in $\mathrm{Al}$ alloys [25]. In particular, EBSD analysis has revealed that the growth direction can change from $\langle 100\rangle$ to $\langle 110\rangle$ in $\mathrm{Al}$ alloys directionally solidified in high thermal gradients [26]. This was considered to be associated with a modification of the atom attachment kinetics when supersaturation is increased. In our cases, the high growth rate together with the supersaturation of $\mathrm{Ti}$ in the B2 phase in our alloy and C, Cr in the D2 steel, may favour different growth directions. Indeed, further theoretical and experimental analyses concerning the LEHCPEB are required to fully understand the growth mechanisms of these grains since it is clear that their nature cannot be explained by conventional growth mechanisms.

The fine austenite structure contributes to the improved tribological properties and corrosion resistance [29-33]. It is already established that the metastable austenite can transform to martensite during wear process and thereby hardens the worn zone and improves the wear resistance. In the case of corrosion, the nanoaustenite will show better corrosion resistance by accelerating the formation of passive film on it. On the other hand, textured surface will also be a positive factor for improving corrosion resistance due to the homogenisation of grains.

\section{Conclusions}

This work has shown the surface nano-structured austenite with specific texture state induced by LEHCPEB irradiation in melting mode through the examples of modified surface layers of AISI D2 steel and NiTi shape memory alloy. In both cases, nanograined austenite with a $\langle 100\rangle+\langle 110\rangle$ fiber texture is formed on the materials after sufficient number of pulses. The results gathered here show the very strong potential for surface nanocrystallization of materials with improved properties by LEHCPEB technique. The mechanisms were identified to produce nanostructures from the melted liquid by taking advantage of the rapid thermal cycle and martensitic transformation generated by the action of the LEHCPEB process.

\section{Acknowledgments}

Professor Kemin Zhang would like to acknowledge the support of the Top Discipline Plan for Mechanical Engineering of Shanghai Municipal Education Commission (YLJX12-2). This work is partially supported by the Special Foundation of the Shanghai Science and Technology Committee for NanoMaterials Research (no. 1052nm05000) and National Natural Science Foundations (nos. 51101096, 51271121). The work of Y. Cai is acknowledged.

\section{References}

[1] A. D. Pogrebnjak, V. T. Shablya, N. V. Sviridenko, A. N. Valyaev, S. V. Plotnikov, and M. K. Kylyshkanov, "Study of deformation states in metals exposed to intense-pulsed-ion beams (IPIB)," Surface and Coatings Technology, vol. 111, no. 1, pp. 46-50, 1999.

[2] M. Sorescu, "The role of magnetostriction in pulsed laser irradiation of amorphous alloys," Journal of Alloys and Compounds, vol. 280, no. 1-2, pp. 251-254, 1998.

[3] D. I. Proskurovsky, V. P. Rotshtein, G. E. Ozur et al., "Pulsed electron-beam technology for surface modification of metallic materials," Journal of Vacuum Science and Technology A, vol. 16, no. 4, pp. 2480-2488, 1998.

[4] C. Dong, A. Wu, S. Hao et al., "Surface treatment by high current pulsed electron beam," Surface and Coatings Technology, vol. 163-164, pp. 620-624, 2003.

[5] Y. Qin, J. X. Zou, C. Dong et al., “Temperature-stress fields and related phenomena induced by a high current pulsed electron beam," Nuclear Instruments and Methods in Physics Research Section B, vol. 225, no. 4, pp. 544-554, 2004.

[6] H. Gleiter, "Nanostructured materials: basic concepts and microstructure," Acta Materialia, vol. 48, no. 1, pp. 1-29, 2000.

[7] M. Tokizane, K. Ameyama, and K. Takao, "Ultra-fine austenite grain steel produced by thermomechanical processing," Scripta Metallurgica, vol. 22, no. 5, pp. 697-701, 1988.

[8] M. Karimi, A. Najafizadeh, A. Kermanpur, and M. Eskandari, "Effect of martensite to austenite reversion on the formation of nano/submicron grained AISI 301 stainless steel," Materials Characterization, vol. 60, no. 11, pp. 1220-1223, 2009.

[9] D. Aisman, H. Jirkova, L. Kucerova, and B. Masek, "Metastable structure of austenite base obtained by rapid solidification in a semi-solid state," Journal of Alloys and Compounds, vol. 509, no. 1, pp. S312-S315, 2011.

[10] K. Lu and J. Lu, "Surface nanocrystallization of metallic materials," Journal of Materials Science \& Technology, vol. 15, no. 3, pp. 193-196, 1999.

[11] K. Lu and J. Lu, "Nanostructured surface layer on metallic materials induced by surface mechanical attrition treatment," Materials Science and Engineering A, vol. 375-377, no. 1-2, pp. 38-45, 2004.

[12] G. Stähli and C. Sturzenegger, "On the formation of austentic boundary layers by short laser-pulse reaction with steel," Scripta Metallurgica, vol. 12, no. 7, pp. 617-622, 1978.

[13] J. X. Zou, T. Grosdidier, B. Bolle, K. M. Zhang, and C. Dong, "Texture and microstructure at the surface of an AISI D2 steel treated by high current pulsed electron beam," Metallurgical and Materials Transactions A, vol. 38, no. 9, pp. 2061-2071, 2007.

[14] K. M. Zhang, D. Z. Yang, J. X. Zou, T. Grosdidier, and C. Dong, "Improved in vitro corrosion resistance of a NiTi alloy by high current pulsed electron beam treatment," Surface and Coatings Technology, vol. 201, no. 6, pp. 3096-3102, 2006.

[15] J. X. Zou, T. Grosdidier, K. M. Zhang, and C. Dong, "Mechanisms of nanostructure and metastable phase formations in the surface melted layers of a HCPEB-treated D2 steel," Acta Materialia, vol. 54, no. 20, pp. 5409-5419, 2006.

[16] Q. P. Meng, Y. H. Rong, and T. Y. Hsu, "Nucleation barrier for phase transformations in nanosized crystals," Physical Review B, vol. 65, no. 17, Article ID 174118, pp. 1741181-1741187, 2002.

[17] J. X. Zou, K. M. Zhang, C. Dong, Y. Qin, S. Hao, and T. Grosdidier, "Selective surface purification via crater eruption under pulsed electron beam irradiation," Applied Physics Letters, vol. 89, no. 4, Article ID 041913, 2006. 
[18] Y. Qin, J. X. Zou, C. Dong et al., “Temperature stress field and related phenomena induced by a high current pulsed electron beam," Nuclear Instruments and Methods in Physics Research Section B, vol. 255, no. 4, pp. 544-554, 2004.

[19] S. Z. Hao, B. Gao, A. M. Wu et al., "Surface modification of steels and magnesium alloy by high current pulsed electron beam," Nuclear Instruments and Methods in Physics Research Section B, vol. 240, no. 3, pp. 646-652, 2005.

[20] K. M. Zhang, J. X. Zou, T. Grosdidier, C. Dong, and D. Z. Yang, "Improved pitting corrosion resistance of AISI $316 \mathrm{~L}$ stainless steel treated by high current pulsed electron beam," Surface and Coatings Technology, vol. 201, no. 3-4, pp. 1393-1400, 2006.

[21] K. M. Zhang, J. X. Zou, T. Grosdidier et al., "Mechanisms of structural evolutions associated with the high current pulsed electron beam treatment of a NiTi shape memory alloy," Journal of Vacuum Science and Technology A, vol. 25, no. 1, pp. 28-36, 2007.

[22] J. X. Zou, Y. Qin, C. Dong, X. G. Wang, A. M. Wu, and S. Z. Hao, "Numercial simulation of thermal-mechanical process of high current pulsed electron beam treatment," Journal of Vacuum Science \& Technology A, vol. 22, no. 3, pp. 545-552, 2004.

[23] H. Jones, Rapid Solidification of Metals and Alloys, institution of metallurgists, London, UK, 1982.

[24] Q. L. Jin, J. P. Eom, S. G. Lim, W. W. Park, and B. S. You, "Grain refining mechanism of a carbon addition method in a $\mathrm{Mg}-\mathrm{Al}$ magnesium alloy," Scripta Materialia, vol. 49, no. 11, pp. 11291132, 2003.

[25] S. Henry, P. Jarry, and M. Rappaz, " $\langle 110\rangle$ dendrite growth in aluminum feathery grains," Metallurgical and Materials Transactions A, vol. 29, no. 11, pp. 2807-2817, 1998.

[26] T. Haxhimali, A. Karma, F. Gonzales, and M. Rappaz, "Orientation selection in dendritic evolution," Nature Materials, vol. 5, no. 8, pp. 660-664, 2006.

[27] A. Sémoroz, Y. Durandet, and M. Rappaz, "EBSD characterization of dendrite growth directions, texture and misorientations in hot-dipped Al-Zn-Si coatings," Acta Materialia, vol. 49, no. 3, pp. 529-541, 2001.

[28] E. Ben-Jacob and P. Garik, "The formation of patterns in nonequilibrium growth," Nature, vol. 343, no. 6258, pp. 523-530, 1990.

[29] K. M. Zhang, J. X. Zou, T. Grosdidier, and C. Dong, "Crater formation induced metastable structure in an AISI D2 steel treated with a pulsed electron beam," Vacuum, vol. 86, no. 9, pp. 1273-1277, 2012.

[30] J. X. Zou, K. M. Zhang, S. Z. Hao, C. Dong, and T. Grosdidier, "Mechanisms of hardening, wear and corrosion improvement of $316 \mathrm{~L}$ stainless steel by low energy high current pulsed electron beam surface treatment," Thin Solid Films, vol. 519, no. 4, pp. 1404-1415, 2010.

[31] Y. Hao, B. Gao, G. F. Tu, H. Cao, S. Z. Hao, and C. Dong, "Surface modification of Al-12.6Si alloy by high current pulsed electron beam," Applied Surface Science, vol. 258, no. 6, pp. 2052-2056, 2012.

[32] Y. Hao, B. Gao, G. F. Tu, S. W. Li, S. Z. Hao, and C. Dong, "Surface modification of Al-20Si alloy by high current pulsed electron beam," Applied Surface Science, vol. 257, no. 9, pp. 39133919, 2011.

[33] K. M. Zhang and J. X. Zou, "Formation of ultrafine twinned austenite on a cold rolled $316 \mathrm{~L}$ stainless steel induced by pulsed electron beam treatment under heating mode," Thin Solid Films, vol. 526, pp. 28-33, 2012. 

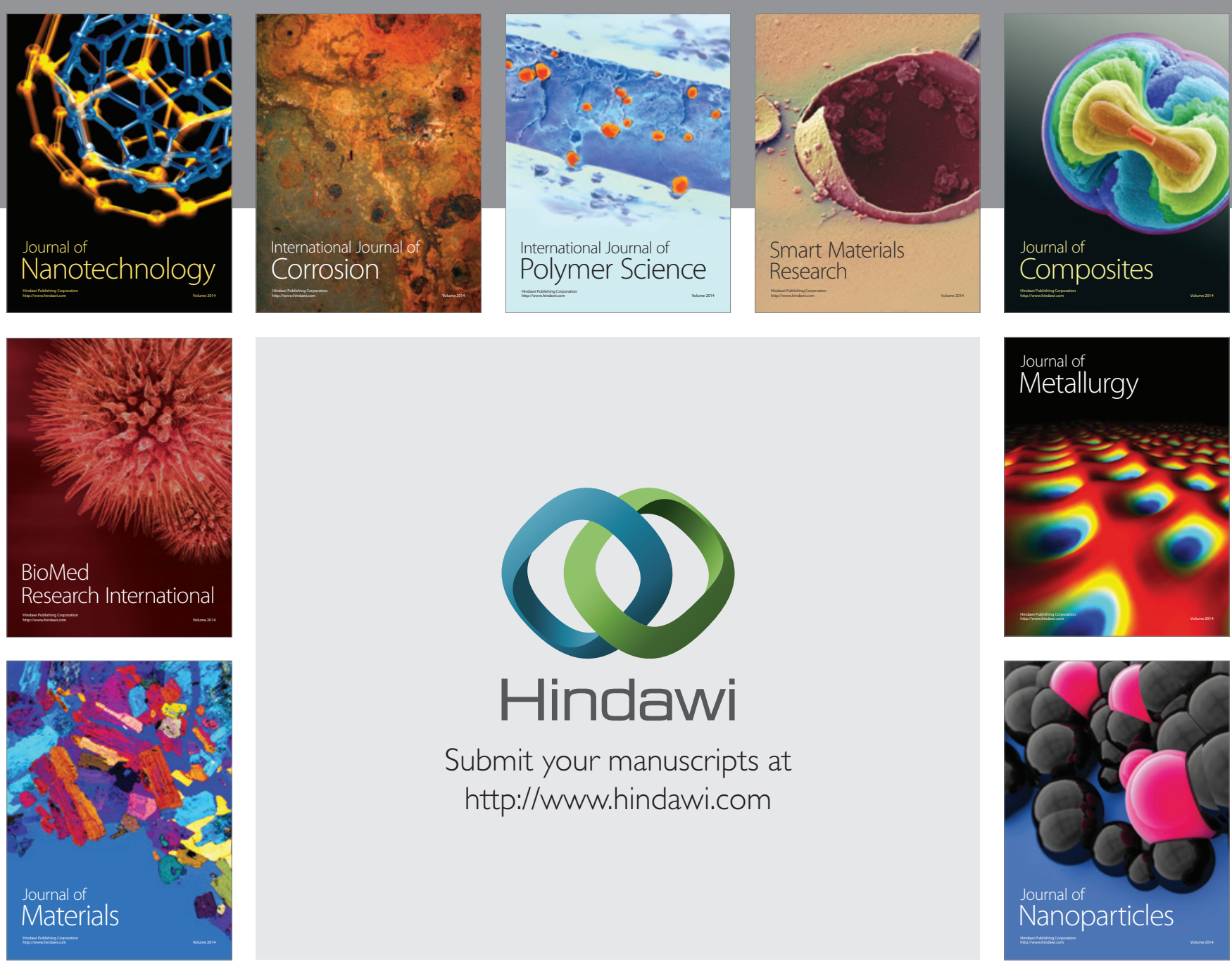

Submit your manuscripts at http://www.hindawi.com
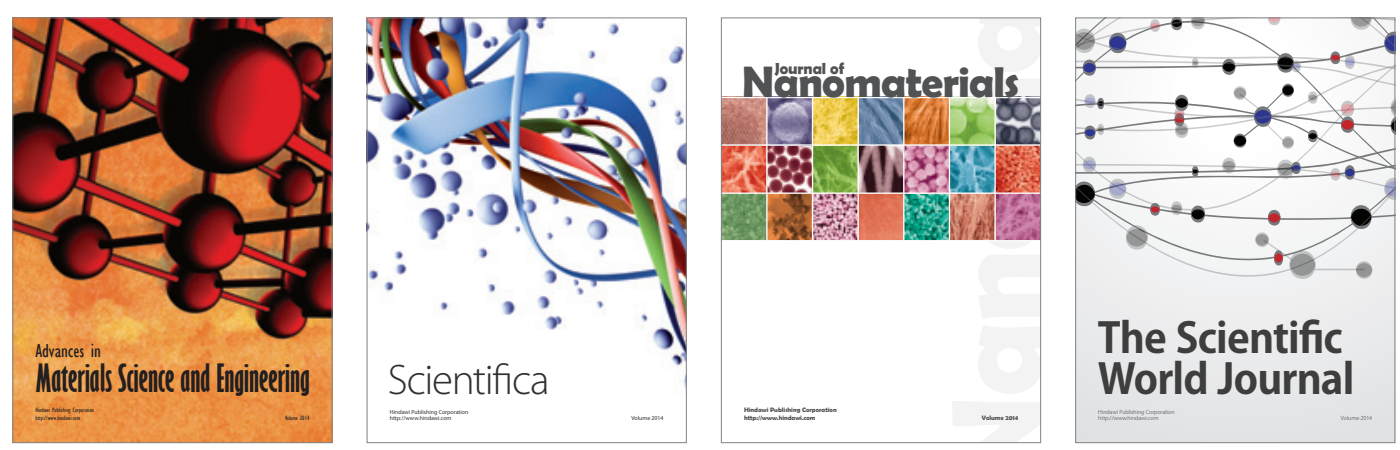

\section{The Scientific World Journal}
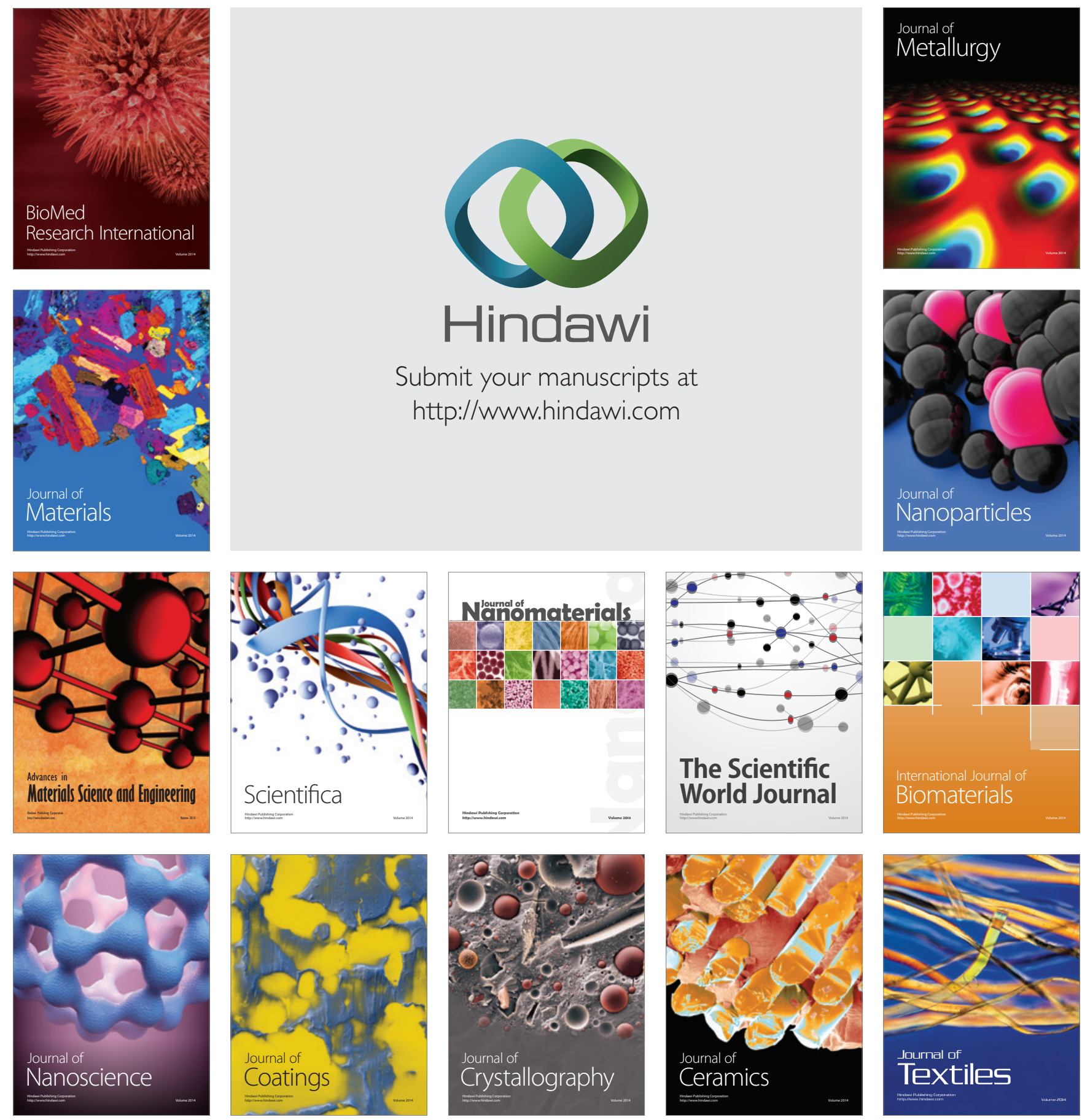